\title{
An Evaluative In Vitro Study of the Effect of the Three Commercially Available Denture Cleansers on Physical Properties of Heat-cured Resin
}

\author{
Divya Puri ${ }^{1}$, Pankaj Dhawan ${ }^{2}$, Pankaj Madhukar ${ }^{3}$, Piyush Tandan $^{4}$
}

\begin{abstract}
Aim: This study aims to evaluate and compare the effect of using three commercially available denture cleansers on surface color, surface roughness, and flexural strength of heat-cured resin.

Materials and methods: A total of 80 rectangular heat-cured acrylic specimens were fabricated and all were immersed in denture cleansers over a period of 6 days in which 30 immersions were performed. Then the physical properties of the heat-cured resin were tested using portable colorimeter, universal testing machine, and surface analyzer. The paired $t$ test was done to compare the before and after immersion values for color, surface roughness, and flexural strength in denture cleansers. The post hoc test was performed to make multiple comparison among different groups.

Results: All heat-cured resin bases presented with changes in color, surface roughness, and flexural strength to some extent when immersed in all the three denture cleansers. The values of change in color, surface roughness, and flexural strength were higher when immersed in Clinsodent as compared to all other groups.

Conclusion: The changes observed in color and surface roughness of all resins samples were within the clinically accepted range while significant decrease in flexural strength was seen on immersion in all three denture cleansers; least change was observed with the Secure denture cleanser. Keywords: Color stability, Denture bases, Denture cleansers, Flexural strength, Surface roughness.

International Journal of Prosthodontics and Restorative Dentistry (2020): 10.5005/jp-journals-10019-1263
\end{abstract}

\section{INTRODUCTION}

As age advances, the rate of complete and partial edentulism is likewise expanding. In this way, the utilization of removable prosthesis has expanded among the older adults, who are essential wearers of dentures. Oral health and general well-being of the patient is affected by edentulism. The placement of denture produces huge changes in the oral environment and adversely affects the integrity of the oral tissues. The patient experiences reduced chewing efficiency and denture-related oral lesions such as angular cheilitis, traumatic ulcer, and denture stomatitis. ${ }^{1}$

The majority of the patients wearing partial and complete denture leaves the dental office with next to no learning about cleaning and maintenance of dentures. This happens because of inability of the clinicians to teach their patients regarding availability and accessibility of various denture-cleaning techniques and aids.

The post-insertion instructions given to the patients are most critical for maintaining oral mucosal health and longevity of the prosthesis. As we know, the denture surface itself can produce a number of favorable changes for the accumulation of bacteria and yeast. The intaglio surface of the dentures usually show micropits and microporosities, which makes it possible for the yeast to nest.

Therefore, the mechanical methods were employed for cleaning the denture but were found to be ineffective in removing the microorganisms completely from the denture surface because of lack of compliance and poor motor coordination due to age. ${ }^{2}$ So, mechanical methods were utilized in conjugation with magnetic stirrers, agitators, sonic vibrators, and ultrasonic devices, yet at same time failed to demonstrate total adequacy in cleaning dentures. $^{3}$
${ }^{1-4}$ Department of Prosthodontics, Manav Rachna Dental College, Faridabad, Haryana, India

Corresponding Author: Divya Puri, Department of Prosthodontics, Manav Rachna Dental College, Faridabad, Haryana, India, Phone: +91 9650490598, e-mail: divya.puri1993@gmail.com

How to cite this article: Puri D, Dhawan P, Madhukar P, et al. An Evaluative In Vitro Study of the Effect of the Three Commercially Available Denture Cleansers on Physical Properties of Heat-cured Resin. Int J Prosthodont Restor Dent 2020;10(1):26-31.

Source of support: Nil

Conflict of interest: None

This led to use of the chemical cleansers as adjunct to mechanical cleaning methods. Chemical cleaners are available in form of creams, pastes, gels, solutions, and tablets. They may include one or combination of various chemical agents such as sodium hypochlorite, enzyme, chlorhexidine, alkaline peroxidase, and diluted acids as the immersion medium for denture cleaning. ${ }^{2}$

But, some chemical agents have been reported to damage acrylic resin by altering the surface properties of the acrylic resin if used for a longer time without following manufacturer's instructions. $^{4}$

The prime physical properties affected by the use of denture cleansers are the flexural strength of acrylic resin. They result in clinical failure of the prosthesis by producing flexural fatigue ${ }^{5}$ and increase the risk of intraoral and extraoral fracture of dentures.

Another important property influenced by use of denture cleansers is the surface roughness. It commonly aids in biofilm 
formation by providing rough irregular areas for retaining the debris and microorganisms. Increased surface roughness can make removal of the biofilm more difficult. ${ }^{6}$ Surface color of the prosthesis is also affects by use of denture cleansers, disturbing the patient the most. It is an indicator of ageing or damage to dental materials. It provides information on serviceability of the material. ${ }^{7}$

This study was undertaken to investigate how different denture cleansers with different compositions and immersion times affect above-mentioned properties of the heat-cured resin as most of them were readily available over the counter. Also to determine the most suitable denture cleanser for heat cure-based denture bases. The null hypothesis for the current study was that there were no effects on physical properties of heat-cured resin bases associated with commercial denture cleansers.

\section{Materials and Methods}

In the present study, a total of 80 heat-cured resin samples were taken as per statistician's recommendation and were divided into four equal groups. Group I was immersed in distilled water (control group). Group II, III, and IV were immersed in three different denture cleansers.

The whole study protocol was divided into eight parts:

\section{Preparation of Metal Mold}

A metal specimen of dimensions $65.0 \times 12.5 \times 3.0 \mathrm{~mm}$ was fabricated by casting according to ADA Specification No. $12 .{ }^{8}$ Two dimples were incorporated on the surface opposite to the test surface to facilitate easy removal of the die without fracture of the gypsum mold.

\section{Preparation of the Gypsum Mold}

Metal dies were invested in a metallic flask face down with type III dental stone. After complete setting of dental stone, a thin layer of petroleum jelly was applied before investing the die for easy removal. At a time, two metal dies were invested in the flask. Later, the flasks were opened and the metal dies were carefully removed keeping the borders of the mold intact. Traces of petroleum jelly were flushed out with hot water and a cold mold seal was applied. The flask was then ready for packing. Required numbers of gypsum molds were prepared by repeating the above-mentioned procedure.

\section{Preparation of Acrylic Specimens}

As per the manufacturer's instruction, the ratio of 3:1 by volume of polymer to monomer is taken. Each flask was painted with a layer of cold mold seal and was packed with acrylic in the dough stage. During trial closure, flashes were removed. The flasks were subjected to pressure in hydraulic press followed by bench cure for 24 hours. The short curing cycle was performed for acrylization of the heat-cured resin that was at $70^{\circ} \mathrm{C}$ for 60 minutes followed by $90^{\circ} \mathrm{C}$ for 30 minutes. The procedure was repeated to fabricate the required number of acrylic samples used for the study. The size of the specimens were confirmed on the digital vernier caliper.

\section{Finishing and Polishing Procedure}

The following procedures were followed in a sequential order: Step 1: All specimen surfaces were finished to the required dimension using tungsten carbide burs of three grits: black, followed by green, and then red at 15,000 rpm.

Step 2: The specimens were then placed in the metal specimen holder and was sequentially sandpapered in a unidirectional motion using three different grits of sandpapers (grit sizes 40-coarse, 60-medium, 100-fine) till the acrylic specimen of required dimension $65.0 \times 12.5 \times 3 \mathrm{~mm}$ was obtained.

Step 3: A slurry of medium-grit pumice mixed in a ratio of 1:1 with water was used with $100 \mathrm{~mm} \times 12.5 \mathrm{~mm}$ cotton buff for 60 seconds at 3,000 rpm on polishing lathe, for polishing. This was repeated with fine-grit pumice. The specimens were then polished for 60 seconds using polishing cakes with separate buffs. All the specimens were to be kept in distilled water for 24 hours before subjecting them for testing.

\section{Immersion Procedure}

The randomly allocated specimens were immersed in beakers containing denture cleansers (Clinsodent D1, Fittydent D2, and Secure D3) and distilled water (control group). All specimens were immersed in such a manner that the surface to be tested faces upward making sure that the solutions covers all the specimens. As per the manufacturer's instructions, the denture-cleansing solutions were prepared, by dissolving one tablet in $200 \mathrm{~mL}$ of warm tap water $\left(40^{\circ} \mathrm{C}\right)$. The immersion time of 30 minutes for D1, 10 minutes for D2, and 5 minutes for D3 was instructed. After immersion time was complete, the resin specimens were removed and washed thoroughly with running water accompanied by drying with an absorbent paper and immersion was repeated. Over a period of 6 days, 30 immersions were performed simulating 180 days of denture cleanser by the patient. Between the immersions, specimens were kept in distilled water at room temperature $\left(23 \pm 2^{\circ} \mathrm{C}\right)$ as the control group.

\section{Color Analysis}

The color change was measured by a portable colorimeter (AMTAST Colorimeter Color Difference Meter $8 \mathrm{~mm}$, Fig. 1) on the immersed side of each specimen. According to the manufacturer's instruction, the supplied white calibration standard was used to calibrate the colorimeter. With the use of CIELab color space, color change $(\Delta E)$ was measured using tristimulus values obtained at several wavelengths in visual spectrum. CIELab represents 3D color space, which comprises of lightness (L), red green (a), and yellow-blue (b).

The color change values $(\Delta E)$ were obtained before and after immersion in denture cleanser solution and were calculated by using following equation:

$$
\Delta E=\sqrt{(\Delta L)^{2}+(\Delta a)^{2}+(\Delta b)^{2}}
$$

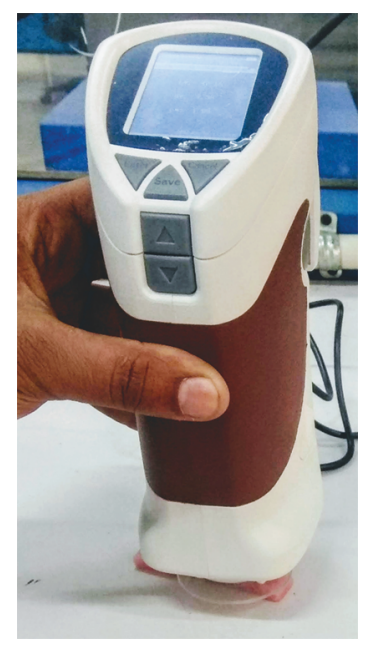

Fig. 1: Color measurement using a portable colorimeter 
To corelate the color difference to the clinical environment, the data were quantified by National Bureau of Standards units (NBS) through formula:

$$
\text { NBS units }=\Delta E \times 0.92
$$

\section{Surface Roughness Test}

To analyze the surface roughness of each rectangular specimen before and after immersion procedures, a surface analyzer (Mitutoyo South Asia Pvt. Ltd, Fig. 2) was used. Three lines were recorded by help of a stylus with a distance of $1 \mathrm{~mm}$ between them and mean arithmetic roughness $R_{\mathrm{a}}$ was calculated. The $R_{\mathrm{a}}$ was used to access surface changes. While $\Delta R_{\mathrm{a}}$ denoted the difference between roughness values obtained before and after immersion of specimens in a denture cleanser.

\section{Flexural Strength Test}

Universal Testing Machine (Saumya Technocrates, Fig. 3) using a three-point bending test was used to measure the flexural strength of specimens.

Flexural strength of rectangular specimen $=$

$$
\mathrm{S}=3 \mathrm{PL} / 2 \mathrm{bd} \mathrm{d}^{2}
$$

Where, $P$ is maximum load, $L$ is distance between the loads, $b$ is specimen width, and $d$ is specimen thickness.

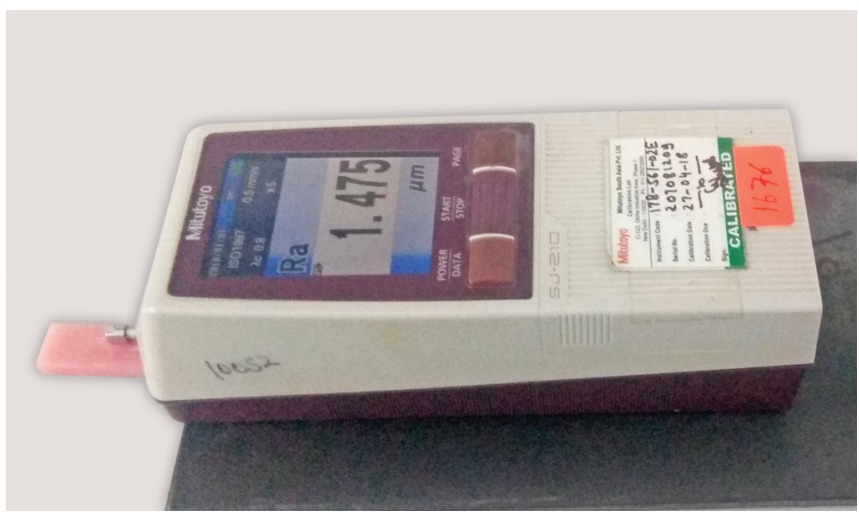

Fig. 2: Surface roughness measurement using a surface analyzer

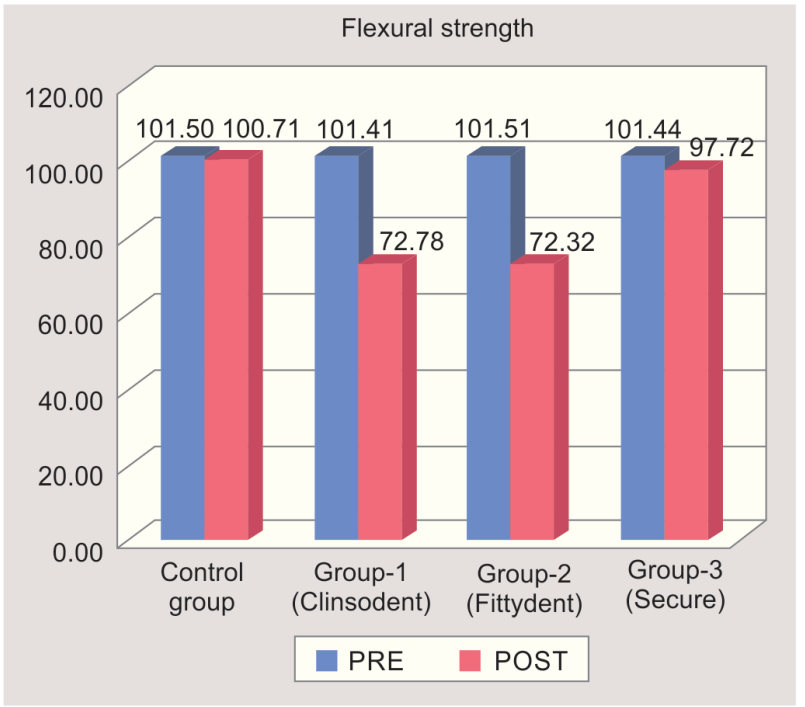

Fig. 4: Comparison of the flexural strengths of all groups
The statistical analysis was performed by using one-way ANOVA followed by the Tukeys HSD post hoc test to compare mean values between more than two groups and the paired $t$ test to compare mean values between the two groups. The $p$ value less than 0.05 was considered as significant at the $95 \%$ confidence level.

\section{RESULTS}

Effects of three commercially available denture cleansers (Clinsodent, Fittydent, and Secure) were evaluated and compared with the control group. There was significant mean difference between the groups post-immersion with $p$ value less than 0.001 . For heat-polymerized acrylic resin, the maximum mean value of flexural strength was noticed in control group (100.71 MPa) and minimum change was observed in the secure denture cleanser (97.72 $\mathrm{MPa}$ ) and maximum change was observed in the Fittydent denture cleanser (72.32 MPa) as seen in Figure 4. The highest mean of color change was observed in the Clinsodent denture cleanser (56.63 NBS unit) while least change was observed in the Fittydent denture cleanser (48.00 NBS units) as seen in Figure 5. With respect to surface roughness, the minimum mean value was noticed in Fittydent $(0.54 \mu \mathrm{m})$ while maximum change was observed in the Clinsodent denture cleanser $(0.71 \mu \mathrm{m})$ as in Figure 6 .

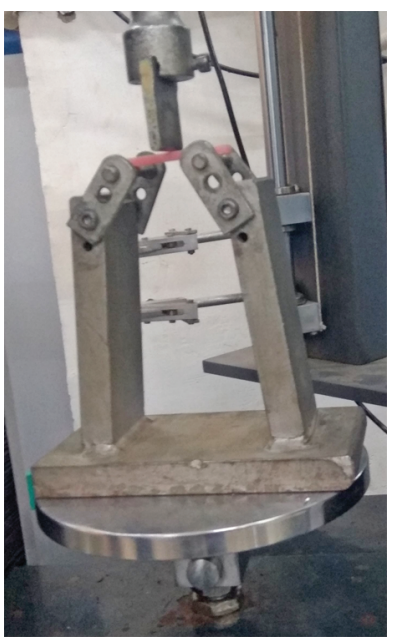

Fig. 3: Flexural strength measured using a universal testing machine

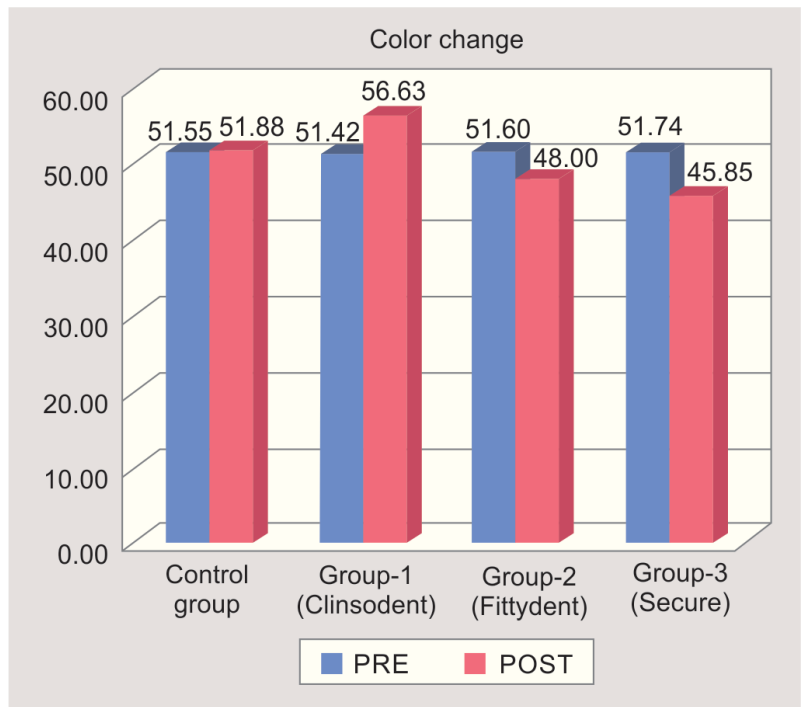

Fig. 5: Comparison of the color change of all groups 


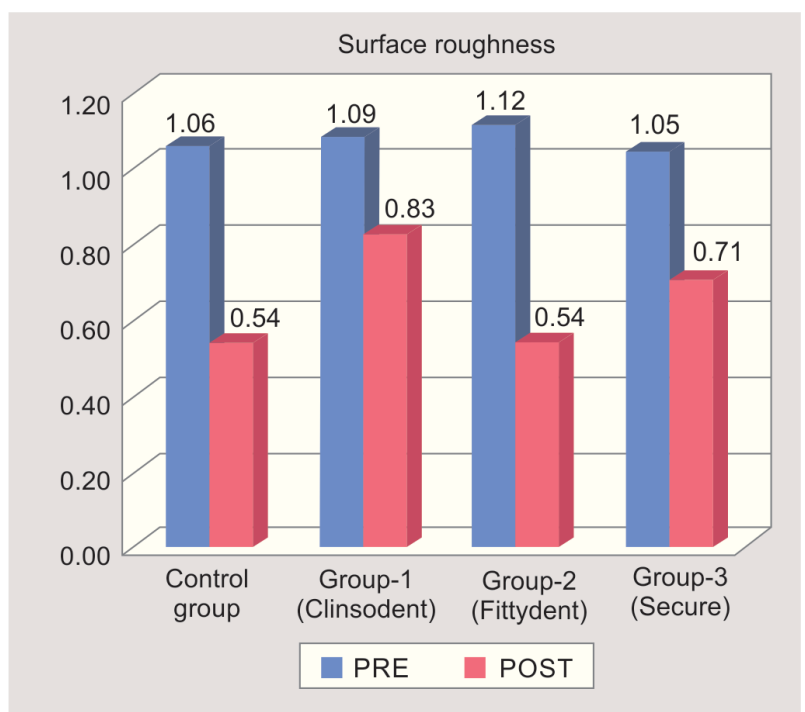

Fig. 6: Comparison of change in the surface roughness of all groups

\section{Discussion}

The oral prosthesis is provided to replace the lost part and also to restore the lost or impaired function due to the missing part or organ of the body. To make it more meaningful, the care and maintenance of the prosthesis is of paramount importance including maintaining hygienic condition. ${ }^{9}$ Inadequate postinsertion home care can compromise the clinical longevity of the prosthesis fabricated utilizing excellent material and techniques.

Poor denture hygiene is considered to have a strong association with oral candidial colonization. In the presence of poor oral hygiene, Candida can stick, penetrate, and aggregate with bacterial communities. And to accelerate this process of adhesion and colonization, surface roughness of denture bases is considered to play a key role. Therefore, it is important to look for measures that completely remove microorganism from colonizing into the denture prosthesis. ${ }^{10}$

Unfortunately, mechanical methods failed in complete removal of microorganisms from dentures. Thus, it is proposed that chemical cleansers are more effective and indispensable in daily denture care, in which hypochlorites, peroxides, enzymes, and acids act as chemical immersion solutions for denture cleaning. However, some chemical agents tend to damage acrylic resin and metal alloys by corroding or staining these alloys as a result of their contact with chlorine or oxygen present in the commercial denture cleanser.

Ideally, immersion in the chemical denture cleanser should not alter the physical, mechanical, and chemical properties of the denture-based acrylic resin. But on contrary, use of these agents do result in changes in surface morphology and flexural strength of denture resins. ${ }^{11}$

However, several studies revealed that the physical, mechanical, and chemical properties of the acrylic resin are affected by denture cleanser. $^{12,13}$

The primary reason for clinical failure of the prosthesis is flexural fatigue of the denture. ${ }^{14}$ The flexural three-point bending test is performed on denture resin because it generates similar type of stresses as applied to the denture during mastication. ${ }^{15}$ As reported by various authors, ${ }^{16,17}$ after complete polymerization reaction, some amount of residual polymethyl methacrylate monomer content remains, which acts as a plasticizer and reduces the interchain forces and yield in early deformation under load which result in reduced flexural strength of denture base acrylics.

To remove this residual monomer, Harrison and Huggett ${ }^{17}$ recommended use of long water bath cycles with terminal boil as it will reduce the levels of the residual monomer by approximately three times. For residual monomer elimination, the specimens of this study were immersed in distilled water. Also the standard acrylization procedure was followed to prepare all acrylic specimens. $^{18}$

Among all the three denture cleansers used, group III showed statistically minimal reduction in values of flexural strength in comparison to other two groups. Smith et al. ${ }^{19}$ explained that if polymerized acrylic resins are immersed in the immersion medium for a longer period, they tend to absorb water continuously which act as a plasticizer reducing the strength of the resin. However, in the above study group III was immersed for the least immersion period of 5 minutes hence producing least reduction in flexural strength.

Beyli et al. ${ }^{20}$ also stated that water sorption by acrylic resin resulted in dimensional instability and fatigue of acrylic resin leading to crack formation and subsequent fracture of the denture. On immersion in Clinsodent, Fittydent, and Secure denture cleansers, reduced flexural strength of the heat-cured acrylic resin was observed in comparison to distilled water immersion in the present study.

The color stability of the prosthesis is the most important factor for determining patients' acceptance for it. ${ }^{21-23}$ In the present study, we have evaluated color change by using the CIEl*a*b* colorimeter system. ${ }^{24,25}$ For the comparison of color and quality control parameters, NBS units were used in the study.

In the present study conducted, it was observed that color change in the control group (distilled water) showed statistically insignificant increase in values the after immersion, similar result was found out in group I which were explained by Pinto et al. ${ }^{26}$ According to him, that water with repeated sorption and desorption cycles produces microcracks, which cause irreversible damage to the acrylic resin. This damage occurs in the form of hydrolytic degradation of the polymer causing damage to ester linkage and weakening the infrastructure of the polymer. Hence creating acrylic zones with different optical properties ${ }^{23}$ that can be esthetically undesirable and can be detected visibly.

According to Robinson et al., ${ }^{27}$ Saraç et al., ${ }^{23}$ and Purnaveja et al., ${ }^{28}$ it was concluded that the solvent present initially penetrates into the intermolecular polymer network and causes expansion of the intermolecular spaces due to water sorption in acrylic resin materials, facilitating leaching out of the intrinsic pigments and penetration of extrinsic colorant in denture cleaning solution which can also cause color change. This could be the probable cause that the acrylic resin used in the study tends to change color as a result of leaching out of the coloring material from the acrylic surface with long-term immersion in distilled water. Later opacity of acrylic resin occurs as a result of monomer leaching out and water getting absorbed on to the surface. ${ }^{29}$

Whereas among groups II and III, group II showed significantly less color change in comparison to group III. Whitening of all acrylic resin occurs due to qualitative difference or $\mathrm{pH}$ difference of the cleaning solution. ${ }^{28}$ Unlü et al. ${ }^{30}$ also observed the whitening effect of the denture base resin, which tends to occur due to the presence 
of deleterious combination of oxidation and strong alkaline solution present in the sodium perborate type of denture cleanser. ${ }^{29}$

The probable cause of color change observed after immersion in the denture cleanser was that these contain sodium perborate which forms an alkaline peroxide solution of $\mathrm{pH}$ ranging from 9 to 11 . Nikawa et al..$^{31,32}$ stated that reason of damage to denture resin when immersed in peroxide-containing denture cleanser was increased the peroxide content and the accelerated level of oxygenation in highly alkaline solution. They have effervescent component such as sodium perborate or sodium bicarbonate, which when dissolved in water form alkaline peroxide solution that decomposes to produce oxygen that loosens the food debris via mechanical means. ${ }^{23,33}$ Therefore, its use results in hydrolysis and decomposition of polymerized acrylic resin itself. This is the reason why the sodium perborate denture cleanser exhibits greater influence on color stability in comparison to any other type of denture cleansers.

Therefore, care must be taken to not expose the denture resin to the peroxide-type denture cleanser for a longer period of time and should instruct the patient to follow the instructions properly.

To increase the adherence of food debris and microorganisms, surface roughness plays a key role as it accelerates the biofilm formation by providing retentive areas and makes it difficult to remove the biofilm from the denture surface. Surface roughness was estimated by value of $R_{\mathrm{a}}$, which gives the average of peaks and depressions on the surface and enables us to evaluate the possibility of bacterial adhesion.

Quirynen and Bollen ${ }^{34}$ also emphasized on importance of having the smooth denture surface because having rough surfaces attracts bacteria, which will adhere to these surfaces for a long period of time making them difficult to be removed by regular hygiene methods. Therefore, recommended surface roughness should be $\leq 2 \mu \mathrm{m}$. Williams and Lewis ${ }^{35}$ also supported the fact. The cited literature also states use of the smooth acrylic surface having roughness of $0.12 \mu \mathrm{m}$, which is well below the critical value of $2 \mu \mathrm{m} .{ }^{36}$

These rough surfaces can be avoided by proper finishing of dentures, which involves both abrading and polishing. Finishing abrasives advocates use of hard and coarse abrasives to remove gross irregularities from the surface, whereas polishing abrasives advocated use of finer particle sizes to smoothen surfaces that had been roughened by finishing abrasives. Therefore, the sample was sandpapered in a unidirectional motion using three different grits of sandpapers (grit sizes 40-coarse, 60-medium, 100-fine) and polished using a rag wheel and pumice slurry. Bollen et al. ${ }^{37}$ reported a positive corelation of the polishing grit to the surface roughness of acrylic resin.

As observed by Harrison et al., ${ }^{38}$ these chemical-based denture cleansers did not contain abrasive particles. Effervescent peroxide or sodium hypochlorite was the main cleansing agents among them. The oxygen is released effectively dislodging debris and creating a plaque-free surface. Duyck et al. ${ }^{39}$ stated that reduced total bacterial count on acrylic removable dentures results if dentures are immersed in denture-cleansing tablets overnight rather than denture storage in water overnight.

It was demonstrated that there was significant less reduction in the surface roughness values observed before and after immersion in group I, where Clinsodent denture cleanser was used as an immersion medium. In the current study, it was observed that surface roughness values reduced after immersion in denture cleansers, which was verified by a study conducted by Garcia et al. ${ }^{40}$ who reported reduced surface roughness of acrylic samples when immersed in a commercial cleanser due to its inability to completely remove pellicle formed on the surface of acrylic.

Peracini et al. ${ }^{41}$ on the other hand stated that the sodium perborate type of denture cleanser did not alter the surface roughness of acrylic resin. However, this inferences varies in studies that have shorter durations and immersion periods. ${ }^{42,43}$ Therefore, it was concluded that while using alkaline peroxides, the time of immersion along with the type of denture base resin used was considered important.

There were some limitations to the above study as there was only one type of heat-cured denture-based acrylic resin used and the parameters like $\mathrm{pH}$ of saliva were not simulated as that of normal saliva. Also the study did not simulate clinical behaviors as it was conducted at room temperature. To overcome this limitation, the in vivo study should be conducted in future along with exploring other mechanical properties of heat cure-resins as well.

\section{Conclusion}

Heat-cured acrylic resins specimen on immersion in distilled water and denture cleanser tablets for 6 days and 30 immersions simulating 180 days of cleanser use by the patient demonstrated noticeable change in surface color, surface roughness, and flexural strength. The change observed in surface color of all denture base resins was within the clinically accepted range and was maximum in Secure followed by Fittydent denture cleansers; least was seen among Clinsodent denture cleansers. The change in surface roughness observed was least in the Fittydent denture cleanser while Clinsodent followed by Secure denture cleanser showed maximum change in surface roughness values. In regard to flexural strength, significant decrease in strength was observed with all three denture cleansers with least reduction observed among Secure denture cleansers while maximum was seen among Clinsodent followed by Fittydent denture cleansers.

\section{References}

1. Al-Fouzan AF, Al-mejrad LA, Albarrag AM. Adherence of Candida to complete denture surfaces in vitro: a comparison of conventional and CAD/CAM complete dentures. J Adv Prosthodont 2017;9(5):402-408. DOI: 10.4047/jap.2017.9.5.402.

2. Jain SG, Magdum D, Karagir A, et al. Denture cleansers: a review. IOSR JDMS 2015;14(2):94-96.

3. Jagger DC, Harrison A. Denture cleansing-the best approach. Br Dent J 1995;178(11):413-417. DOI: 10.1038/sj.bdj.4808788.

4. Porwal A, Khandelwal M, Punia V, et al. Effect of denture cleansers on color stability, surface roughness, and hardness of different denture base resins. JIPS 2017;17(1):61-67. DOI: 10.4103/0972-4052.197940.

5. Stafford GD, Smith DC. Flexural fatigue tests of some denture base polymers. Br Dent J 1970;128(9):442-445. DOI: 10.1038/sj.bdj.4802483.

6. Berger JC, Driscoll CF, Romberg E, et al. Surface roughness of denture base acrylic resins after processing and after polishing. J Prosthodont 2006;15(3):180-186. DOI: 10.1111/j.1532-849X.2006.00098.x.

7. Shotwell JL, Razzoog ME, Koran A. Color stability of long term soft denture liner. J Prosthet Dent 1992;68(5):836-838. DOI: 10.1016/00223913(92)90213-t.

8. International Organization for Standardization. ISO 1567:1998. Dentistry: denture base polymers. Geneva, Switzerland 1998.

9. Dhamande MM, Pakhan AJ, Thombare RU, et al. Evaluation of efficacy of commercial denture cleansing agents to reduce the fungal biofilm activity from the heat polymerized denture acrylic resin: an in-vitro 
study. Contemp Clin Dent 2012;3(2):168-172. DOI: 10.4103/0976237X.96820.

10. Yoshikawa TT. Perspective: aging and infectious diseases. past, present, and future. J Infect Dis 1997;176(4):1053-1057. DOI: 10.1086/516547.

11. Asad T, Watkinson AC, Huggett R. The effect of disinfection procedure on flexural properties of denture base acrylic resins. J Prosthet Dent 1992;68(1):191-195. DOI: 10.1016/0022-3913(92)90303-r.

12. McNeme SJ, Von Gonten AS, Woolsey GD. Effects of laboratory disinfecting agents on color stability of denture acrylic resins. J Prosthet Dent 1991;66(1):132-136. DOI: 10.1016/0022-3913(91)90359-5.

13. Arab J, Newton JP, Lloyd CH. The effect of an elevated level of residual monomer on the whitening of a denture base and its physical properties. J Dent 1989;17(4):189-194. DOI: 10.1016/03005712(89)90073-0.

14. Chitchumnong P, Brooks SC, Stafford GD. Comparison of three- and four-point flexural strength testing of denture base polymers. Dent Mater 1989;5(1):2-5. DOI: 10.1016/0109-5641(89)90082-1.

15. Yunus N, Rashid AA, Azmi LL, et al. Some flexural properties of a nylon denture base polymer. J Oral Rehabil 2005;32(1):65-71. DOI: 10.1111/j.1365-2842.2004.01370.x.

16. Grajower R, Goultschin J. The transverse strength of acrylic resin strips and of repaired acrylic samples. J Oral Rehabil 1984;11(3):237-247. DOI: 10.1111/j.1365-2842.1984.tb00573.x.

17. Harrison A, Huggett R. Effect of the curing cycle on residual monomer levels of acrylic resin denture base polymers. J Dent 1992;20(6): 370-374. DOI: 10.1016/0300-5712(92)90031-7.

18. American Dental Association. Revised american dental association specification $\mathrm{n}^{\circ} 12$ for denture base polymers. J Am Dent Assoc 1975;90(2):451-458. DOI: 10.14219/jada.archive.1975.0069.

19. Smith LSA, Schmitz V. The effect of water sorption on the glass transition temperature of poly(methyl methacrylate). Polymer (Guildf) 1988;29(10):1871-1878. DOI: 10.1016/0032-3861(88)90405-3.

20. Beyli MS, Von Fraunhofer JA. An analysis of cause of fracture of acrylic resin dentures. J Prosthet Dent 1981;46(3):238-241. DOI: 10.1016/00223913(81)90206-7.

21. Polyzois GL, Yannikakis SA, Zissis AJ, et al. Color changes of denture base materials after disinfection and sterilization immersion. Int J Prosthodont 1997;10(1):83-89.

22. Anil N, Hekimoglu C, Sachin S. Color stability of heat polymerizing and autopolymerizing softdenture liner. J Prosthet Dent 1999;81(4): 481-484. DOI: 10.1016/s0022-3913(99)80018-3.

23. Saraç D, Saraç YS, Kurt M, et al. The effectiveness of denture cleansers on soft denture liners colored by food colorant solution. J Prosthodont 2007;16(3):185-191. DOI: 10.1111/j.1532-849X.2006.00170.x.

24. $\mathrm{CIE}$ (Commision internationale de l'Eclairage). Colorimetry-technical report, CIE Pub No.15 3rd ed, Vienna: Bureau Central de La CIE; 2004. pp. $16-20$.

25. Wyszecki G, Stiles WS. Color science: concept and methods, quantative data and formulae 2nd ed., New York: Wiley-Interscience; 1982. 113-116.

26. Pinto Lde R, Acosta EJ, Távora FF, et al. Effect of repeated cycles of chemical disinfection on the roughness and hardness of hard reline acrylic resins. Gerodontology 2010;27(2):147-153. DOI: 10.1111/j.17412358.2009.00282.x.

27. Robinson JG, McCabe JF, Stores R. The whitening of acrylic dentures: the role of denture cleansers. Br Dent J 1985;159(8):247-250. DOI: 10.1038/sj.bdj.4805694.
28. Purnaveja S, Fletcher AM, Ritchie GM, et al. Color stability of two self-curing denture base materials. Biomaterials 1982;3(4):249-250. DOI: 10.1016/0142-9612(82)90029-1.

29. Devlin H, Kaushik P. The effect of water absorption on acrylic surface properties. J Prosthodont 2005;14(4):233-238. DOI: 10.1111/j.1532849X.2005.00050.x.

30. Unlü A, Altay OT, Sahmali S. The role of denture cleansers on the whitening of acrylic resins. Int J Prosthodont 1996;9(3):266-270.

31. Tan H, Woo A, Kim S, et al. Effect of denture cleansers, surface finish, and temperature on molloplast B resilient liner color, hardness, and texture. J Prosthodont 2000;9(3):148-155. DOI: 10.1053/ jopr.2000.18551.

32. Nikawa $\mathrm{H}$, Hamada $\mathrm{T}$, Yamashiro $\mathrm{H}$, et al. A review of in vitro and in vivo methods to evaluate the efficacy of denture cleansers. Int J Prosthodont 1999;12(2):153-159.

33. Nikawa $\mathrm{H}$, Hamada $\mathrm{T}$, Yamashiro $\mathrm{H}$, et al. Effect of denture cleansers on direct soft denture lining materials. J Prosthet Dent 1994;72(6): 657-662. DOI: 10.1016/0022-3913(94)90300-x.

34. Quirynen $M$, Bollen $C M$. The influence of surface roughness and surface-free energy on supra-and sub-gingival plaque formation in man. A review of literature. J Clin Periodontol 1995;22(1):1-14. DOI: 10.1111/j.1600-051x.1995.tb01765.x.

35. Williams DW, Lewis MAO. Isolation and identification of candida from the oral cavity. Oral Dis ISRN Dentistry 2011. 1-7. DOI: [doi:10.5402/2011/487921].

36. Ural C, Sanal FA, Cengiz S. Effect of different denture cleansers on surface roughness of denture base materials. Clin Dent Res 2011;35(2):14-20.

37. Bollen CM, Lambrechts P, Quirynen M. Comparison of surface roughness of oral hard materials to the threshold surface roughness for bacterial plaque retention: a review of the literature. Dent Mater 1997;13(4):258-269. DOI: 10.1016/s0109-5641(97)80038-3.

38. Harrison Z, Johnson A, Douglas CW. An in vitro study into the effect of a limited range of denture cleaners on surface roughness and removal of Candida albicans from conventional heat-cured acrylic resin denture base material. J Oral Rehabil 2004;31(5):460-467. DOI: 10.1111/j.1365-2842.2004.01250.x.

39. Duyck J, Vandamme K, Krausch-Hofmann S, et al. Impact of denture cleaning method and overnight storage condition on denture biofilm mass and composition: a cross-over randomized clinical trial. PLoS ONE 2016;11(1):e0145837. DOI: 10.1371/journal.pone. 014583].

40. Garcia RCMR, Junior JA, Rached RN, et al. Effect of denture cleansers on the surface roughness and hardness of a microwave-cured acrylic resin and dental alloys. J Prosthodont 2004;13(3):173-178. DOI: 10.1111/j.1532-849X.2004.04028.x.

41. Peracini A, Davi LR, Ribeiro NQ, et al. Effect of denture cleansers on physical properties of heat-polymerized acrylic resin. J Prosthodont Res 2010;54(2):78-83. DOI: 10.1016/j.jpor.2009.11.004.

42. Machado AL, Breeding LC, Vergani CE, et al. Hardness and surface roughness of reline and denture base acrylic resins after repeated disinfection procedures. J Prosthet Dent 2009;102(2):115-122. DOI: 10.1016/S0022-3913(09)60120-7.

43. Silva FC, Kimpara ET, Mancini MN, et al. Effectiveness of six different disinfectants on removing five microbial species and effects on the topographic characteristics of acrylic resin. J Prosthodont 2008;17(8):627-633. DOI: 10.1111/j.1532-849X.2008. 00358.x. 